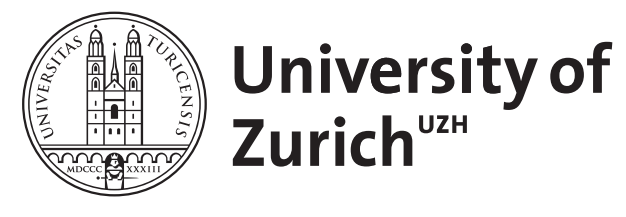

\title{
On the use and usefulness of backup plans
}

\author{
Napolitano, Christopher M ; Freund, Alexandra M
}

\begin{abstract}
In this article, we introduce the concept of backup plans as a motivational construct, defined as alternative means to an end that are intentionally developed but are not initially (or ever) used. We posit that backup plans change the way that a person pursues a goal, as well as the likelihood of achieving it, even if the backup plans are never used. In some cases, backup plans are a safety net supporting goal pursuit; however, in other cases, they constitute an unnecessary expense that can undermine motivation to persist with a first-choice plan. We propose that variations in the use and usefulness of backup plans are based on a person's estimation and regulation of complexity value, or the additional costs and benefits that having a backup plan introduces compared with pursuing the same goal with only a single means. Although variations in the estimation and regulation of complexity value are idiosyncratic products of individual, contextual, and goal-related factors, we provide the prototypical example of age-related differences to illustrate our key points. In sum, our conceptualization of backup plans represents a new synthesis of motivation, multiple-goal, and life-span developmental research that addresses a key lacuna in the self-regulation literature.
\end{abstract}

DOI: https://doi.org/10.1177/1745691615596991

Posted at the Zurich Open Repository and Archive, University of Zurich

ZORA URL: https://doi.org/10.5167/uzh-122591

Journal Article

Accepted Version

Originally published at:

Napolitano, Christopher M; Freund, Alexandra M (2016). On the use and usefulness of backup plans. Perspectives on Psychological Science, 11(1):56-73.

DOI: https://doi.org/10.1177/1745691615596991 
Running Head: BACKUP PLANS

On the Use and Usefulness of Backup Plans

Christopher M. Napolitano ${ }^{1}$ and Alexandra M. Freund ${ }^{1,2}$

${ }^{1}$ University of Zurich, Dept. of Psychology, ${ }^{2}$ University Research Priority Program Dynamics of Healthy Aging, University of Zurich

\section{TO BE PUBLISHED IN PERSPECTIVES ON PSYCHOLOGICAL SCIENCE}

Author Note

Christopher M. Napolitano and Alexandra M. Freund, Department of Psychology, University of Zurich, Switzerland. Alexandra M. Freund is also affiliated with the University Research Priority Program Dynamics of Healthy Aging, University of Zurich.

This research is supported by the Swiss National Science Foundation Grant 100014138045 "Readiness to Disengage from Motivational Conflict: Adult Age Differences and Implications for Emotional Experiences” (PI: A. M. Freund) and the Suzanne and Hans Biäsch for Foundation for Applied Psychology Grant 2014/14 “Time for Plan B? Testing for age-related differences in the use, utility, and efficiency of backup plans" (PI: C. M. Napolitano). We would like to thank the members of the Life-Management Lab for valuable input into this research.

Correspondence concerning this article should be addressed to either author at Department of Psychology, University of Zurich, Binzmuehlestrasse 14/11, 8050 Zurich, Switzerland.E-mail: napolitano@ psychologie.uzh.ch or freund@psychologie.uzh.ch 


\begin{abstract}
This article introduces the concept of backup plans as a motivational construct, defined as alternative means to an end that are intentionally developed but not initially (or ever) used. We posit that backup plans change the way a person pursues a goal, as well as the likelihood of achieving it, even if they are never used. In some cases, backup plans are a safety net supporting goal pursuit, but in others they constitute an unnecessary expense that can undermine motivation to persist with a first-choice plan. We propose that variations in the use and usefulness of backup plans are based on a person's estimation and regulation of complexity value, or the additional costs and benefits that having a backup plan introduces, compared to pursuing the same goal with only a single means. Although variations in the estimation and regulation complexity value are idiosyncratic products of individual, contextual, and goal-related factors, we provide the prototypical example of age-related differences to illustrate our key points. In sum, our conceptualization of backup plans represents a new synthesis of motivation, multiple-goal, and life-span developmental research that addresses a key lacuna in the self-regulation literature.
\end{abstract}

(Word Count: 190)

Keywords: goals; life-span development; motivation; self-regulation; complexity value 
On the Use and Usefulness of Backup Plans

Imagine a photographer who wants to capture a perfect sunset panorama. Unsure which lens will provide the best picture, he attaches a standard zoom to his camera, and quickly packs three other lenses in his (now quite heavy and cumbersome) bag. He thinks, "It's good that I'm carrying all these alternate lenses - now I'll definitely get the perfect picture!" As he hikes to the vantage point, the extra weight in his bag slows his ascent. He makes it to the top with little time to spare. Still deliberating which lens is best to use, he misses the perfect moment for a photograph. He decides that for tomorrow's sunset, he will hike up with only one lens.

The twists and turns of goal pursuits, photographic or otherwise, are difficult to predict. Although recent work conceptualized specific actions that a person can use to maximize gains from unexpected, serendipitous events (Napolitano, 2013), and there is quite some literature on how people react to failures once they occur (e.g., Dweck \& Leggett, 1988), there is little psychological research on the means people set aside for potential setbacks or failures, which we term backup plans. Our central thesis is that having a backup plan changes the way a person pursues a goal, as well as his or her likelihood of achieving it, even if it is not currently or ever used. The basic question of this article is: When are backup plans a prudent safety net supporting efficient goal pursuit, and when are they an unnecessary expense that can interfere with a firstchoice plan and compromise goal striving? In other words: When do backup plans support, and when do backup plans undermine self-regulation? We address this question across four core premises.

(1) People make backup plans in an attempt to manage uncertainty. Our world is probabilistic; it is never guaranteed that a person's means will necessarily lead to their desired ends. One of the hallmarks of self-regulation is to manage this uncertainty and to cope with 
setbacks or failures to reach one's goals.

(2) Backup plans introduce additional complexity into goal pursuit. Although having backup plans available clearly provides benefits in some situations, managing a more complex means strategy consisting of a primary and one or more backup plans can come at the cost of distracting goal-related or motivational resources away from the active first-choice plan. At any given moment, the difference between the benefit-cost ratios $^{1}$ of the complex backup plan approach and the simpler single means approach is termed the complexity value. When complexity value is positive, backup planning provides a better benefit/cost ratio than a single-means approach. When complexity value is negative, the single-means approach provides a better value.

(3) A person's estimation of the complexity value at the end of goal pursuit underlies their decision to use (that is, make) backup plans, but a person's regulation of complexity values during the goal pursuit underlies their usefulness. We propose that people who make backup plans use their projections of complexity value as a heuristic, assessing that their backup plan's additional inefficiencies may be "worth it in the end" if the backup plan is indeed necessary. We argue that this heuristic is flawed because it underestimates the additional costs of reserving backup plans while they are not used. Therefore, contrary to a person's expectations, backup plans' additional costs (e.g., the extra time it takes the photographer to hike up the mountain; the extra time he takes deliberating which lens to use) can interfere with first-choice means and lead to goal failure. Therefore, in order for backup plans to be useful, people must keep these inefficiencies in check by regulating complexity value across goal pursuit.

(4) There are a variety of individual, contextual, and goal-related factors that influence the estimation and regulation of complexity value, and thus, the use and usefulness of backup plans. Describing each of these influences is outside the scope of this article. In the current article, we 
take a life-span developmental perspective (Baltes, 1987) to hypothesize age-related differences as a prototypical example of variations backup plans' use and usefulness.

\section{Defining and introducing the key concepts of backup plans}

Before returning to these core premises, this section begins by defining backup plans as a motivational construct and introducing backup plans' key processes. We define backup plans as alternative means to an end that are intentionally developed but not initially (or sometimes, ever) used. In other words, backup plans are means that a person holds back for potential later use for achieving a goal. Both backup plans and first-choice plans are perceived to be equifinal, or means that can lead to achieving the same goal (von Bertalanffy, 1968; see also Ford \& Lerner, 1992; Overton, 2010). We posit that backup planning involves three processes: A person (1) develops a backup plan from the set of means that equifinally lead to a goal. Unlike using multiple means concurrently, backup plans are (2) reserved, initially unused for various reasons but available to (3) replace a first-choice plan should they become suitable or the first-choice plan prove unsuitable.

Replacing the first choice plan with a backup plan involves fully substituting it for a failing or limited first-choice plan. There are other ways that a backup plan's status may change across a goal pursuit. For example, a backup plan can later become a simultaneously implemented and complementary means to achieve a goal (e.g., the backup plan to go swimming in order to increase fitness might become complementary to the first-choice plan of walking when a person realizes that employing both plans serves her fitness goal best). However, in this case we would no longer speak of a backup plan but instead of a two-pronged approach to goal pursuit. Alternatively, a person may discard a backup plan that they developed if it is no longer suitable. Although these changes to backup plans are worthy of future inquiry, we focus on the 
developing, reserving, and replacing processes in this work.

\section{Theoretical bases for backup plans in the self-regulation literature}

Research on multiple goal pursuit informs our concept of backup plans. In everyday life, people rarely pursue a single end with a single means. A person's goals are organized into complex systems with varying hierarchies, dependencies, and relations (Shah \& Kruglanski, 2008). Balancing the demands of these multiple goals is challenging, as the amount of resources available for any goal pursuit (e.g., hours in a day) are finite (Baltes, Staudinger, \& Lindenberger, 1999). With these limitations, people selectively invest their resources in a small number of goals to maximize their potential for adaptive development (Freund, 2008). However, given one's obligations or motivations, the selectivity required for optimal performance on one's goals is not always possible. For example, uncomfortable consequences could result from disengaging from domestic responsibilities in order to maintain peak physical fitness. When faced with the inevitability of pursuing multiple goals simultaneously, people adopt various approaches to managing multiple goal pursuit, such as focusing different goals in the most important life domains (e.g., Riediger \& Freund, 2006) or electing to pursue their multiple goals sequentially, rather than simultaneously (Orehek \&Vazeou-Nieuwenhuis, 2013; Wiese \& Freund, 2000).

Comparatively little work has explored the effects of pursuing ends with multiple means. The existing work describes the role of means that are used concurrently, rather than means that are reserved (i.e., backup plans). Nevertheless, this research has implications for this discussion. For instance, Kruglanski and colleagues (Kruglanski, Pierro, \& Sheveland, 2011) illustrated that using multiple means at the same time decreases the commitment to using any one means, while also increasing overall commitment to the goal. Relatedly, Huang and Zhang (2013) showed that 
beginning a goal pursuit by using multiple concurrent means may be adaptive in that it provides people with several potential paths to success. However, using multiple means as the goal nears its completion can be distracting and a maladaptive use of finite resources.

There are several reasons why people may make backup plans over using multiple means concurrently. Because a backup plan is developed but not initially used, it can provide a ready "safety net" if one's first option proves insufficient. In addition, because backup plans are reserved for later use, they may divert fewer resources away from one's first-choice plan compared to concurrently-used means. Finally, a person may resort to a backup plan when using more than one means is not possible or is too costly, thus not allowing concurrent use of multiple means. In this light, developing backup plans can be akin to "eating your cake and having it too" - an attempt to reap the benefits of having multiple means available, while at the same time also selectively investing one's finite resources.

However, there are situations in which backup plans can actively interfere with goal achievement. For example, the backup plan might undermine efficient goal pursuit by keeping an alternative to the first-choice plan active, thereby making a person constantly aware of the things that she is missing (e.g., the academic who thinks of all the money she could make in consulting if she stopped her academic job; constantly comparing her career with the backup plan could interfere with her research or teaching). This returns us to our basic question: When are backup plans harmful, and when are they useful? Because there is a limited literature that pertains directly to backup plans, we next turn to related theoretical approaches to help conceptualize the underlying self-regulatory processes that determine their use and usefulness.

\section{Integrating backup plans into the SOC model}

We consider developing and replacing to be special instances of optimization and 
compensation, respectively, as conceptualized in the model of Selection, Optimization, and Compensation (SOC; e.g., Baltes \& Baltes 1990; Freund \& Baltes, 2002). In the SOC model, optimization involves acquiring, applying, coordinating, and maintaining means for achieving a goal (e.g., Freund \& Baltes, 2002). People engage in optimizing actions to improve their chances for goal achievement. Examples of optimization include learning and practicing skills to improve performance in the athletic or education domains. For many goals, there is no single "formula" for success. Goals can often be accomplished by multiple means within a broader equifinality set, i.e., the set of the means that can lead to achieving the goal (Kruglanski, Shah, Fishbach, Friedman, \& Chun, 2002). In some cases, a person may elect to use one means from this set in an attempt to optimize his or her chances of achieving a goal. In other cases, people may decide on using multiple means concurrently as the optimal approach (e.g., swimming and walking to improve fitness; Kruglanski, et al., 2011). Backup plans are an additional category of equifinal optimizing means, wherein a person identifies that there may be more than one way to achieve a goal, but chooses to begin working on the goal by using a first-choice plan, reserving a backup plan for potential later use. For example, the earlier described photographer chose to attach a standard zoom lens to his camera, while reserving the backup lens options by taking them with him to the photo location. Again, note that the backup plan can become a first choice plan such as when the photographer will switch to one of the backup lenses as his standard one. In this case, the first choice and the backup plan trade places as the former standard lens now becomes the backup.

In some cases, a backup plan may be perceived as inferior to a first-choice plan. For example, our photographer may have thought that the standard zoom was the option that best fit the anticipated conditions. However, not every backup plan is necessarily inferior to a first- 
choice plan. For some goals, two means may be perceived to be equally effective, but they cannot logistically be used concurrently because the two means are incompatible (e.g., wanting to impress a new acquaintance by being spontaneous and prudent at the same time) or because resources are insufficient to invest in both means at the same time (e.g., paying for a tutor and taking an expensive course to learn a new language). In these cases, in order to be able to act at all, a person must choose one means over the other, and may reserve the second means as a backup plan. Imagine that you want to learn a new instrument and you consider taking cello or piano lessons but cannot do both due to time constraints. Given that you have no clear preference for either of the two instruments, you start with the cello and delegate the piano to be your backup plan. In situations like these, a person's initial choice to use one means and reserve the other can be more-or-less random.

Regardless of whether one's backup plans are perceived to be inferior to the first-choice plan or not, the motivation to develop backup plans remains the same. Returning to our first core premise, we posit that people develop backup plans to optimize their chances of achieving a goal, attempting to reduce uncertainty though investing in means "insurance" that can efficiently replace a first-choice plan should it prove unsuitable for goal achievement. In the cello/piano example, if it turns out that your sense of pitch is not sufficient to learn a string instrument, having piano as a backup plan might help you to cope with your musical limitations and maintain your motivation to learn an instrument. In this sense, developing backup plans can be considered a special instance of optimization within the SOC model.

However, replacing with a backup plan can, in some cases, be considered a special instance of compensatory action. In the SOC model, compensation refers to attempts to minimize actual or impending losses by augmenting or substituting available means (Freund, 2008). A mundane 
example of compensation in terms of replacing with a backup plan is taking the train to work when one's bicycle has a flat tire. In this example, the compensatory action involves replacing the first-choice plan with a backup plan when the initial means is no longer available to use due to a loss. Not every compensatory decision to use backup plans is as straightforward as "take thetrain if your tire is flat." As we describe later, choosing to compensate by replacing with a backup plan can prove motivationally challenging.

\section{Reserving backup plans from a self-regulatory perspective}

To review, developing backup plans could broadly be considered an optimizing action that maximizes one's chances of achieving a goal, whereas replacing first-choice plans can be a compensatory action enacted in response to (actual, anticipated, or relative) losses concerning the first-choice plan. However, the SOC model does not adequately describe one of the central processes of backup planning, namely reserving. People can reserve backup plans with different motivations and for different reasons. Some backup plans may be reserved to minimize losses from specific predicted shortcomings, while other backup plans may be reserved because they could maximize gains by proving more suitable than one's first-choice plan.

\section{Comparing and contrasting reserving to other self-regulatory concepts: The example} case of contingency. Overall, backup plans are reserved because they may later prove useful for managing uncertainty in goal pursuit. This potential usefulness can be conceptualized in two ways: contingency and redundancy. We begin by describing contingent backup plans.

For some goals, a person's first-choice plans might fail in a foreseeable, predictable way. For example, one may reach or near a "developmental deadline," (Heckhausen, 1999) or suffer specific predictable losses to goal-relevant resources (e.g., injuring a susceptible joint when pursuing the goal to exercise regularly). Whatever the case, people may develop and reserve 
backup plans because they could later address these contingency conditions, or specific anticipated losses resulting from or pertinent to the first-choice plan. These contingent backup plans are placed and remain in reserve until one nears or passes the contingency condition. For an example of a contingent backup plan, imagine an older adult with the goal to maintain physical fitness until her next medical appointment. Her first-choice plan is brisk walking, but she develops swimming as a backup plan in case her troublesome knee causes her discomfort.

There are similarities between contingent backup plans and the concept of implementation intentions (e.g., Gollwitzer, 1999). Implementation intentions involve linking anticipated situations to specific goal-related behavioral responses. An example of an implementation intention is "I will go jogging for 45 minutes (specifying the "what") every Monday, Wednesday, and Friday evening after coming home from work (specifying the "when") along the lake (specifying the "where")." A person develops implementation intentions to efficiently respond to potential future situations that may arise during goal pursuit. This increased efficiency comes from two sources. First, because the activation of implementation intentions is tied to specific situations, a person's mental representation of this situation is made more accessible, and thus easier to detect. The second source of efficiency is a result of implementation intentions' assumed automaticity (Bargh \& Chartrand, 1999; Bargh, Schwader, Hailey, Dyer, \& Boothby, 2012). Gollwitzer posits that implementation intentions are automatically enacted once the situation is encountered, thus "passing the control of one's behavior to the environment" (Gollwitzer, 1993, p. 173).

Like implementation intentions, contingent backup plans involve linking future actions to specific anticipated contingency conditions. Also consistent with implementation intentions, a person is unlikely to use a contingent backup plan if the contingency condition does not occur. 
Therefore, keeping contingent backup plans in reserve may involve relatively low resource costs.

That is, there is little temptation to use (or consider using) a contingent backup plan in the absence of the contingency condition. In the example case of our older adult, she does not seriously consider swimming as long as her knees are healthy. However, contingent backup plans differ from implementation intentions in that taking contingent backup plans out of reserve is more likely an intentional action rather than automatized process. There are two reasons for this distinction. First, implementation intentions typically refer to the association between situational cues and one action plan. In some cases, implementation intentions specify supplementary actions supporting a first-choice plan that are temporarily enacted in response to the contingency condition (Stadler, Oettingen, \& Gollwitzer, 2009, 2010). In contrast, contingent backup plans wholly replace the first-choice plan as the primary means for goal achievement, which requires intentionally re-allocating resources to support the (former) backup plan. For example, to be able to replace walking with swimming after knee pain, our older adult must purchase a swimsuit and swim goggles.

Second, this intentional re-allocation can be made more difficult because by simply committing to the first-choice plan, the backup plan might be perceived as inferior. Even when the contingency condition is present, a person may be reticent to take the contingent backup plan out of reserve because the behavioral commitment to the original plan might take on a life of its own. Pursuing a goal using specific means can strengthen the association of the means with the desired ends and thereby increase the perceived value or instrumentality of these means (Labroo \& Kim, 2009). To illustrate this point, let us again return to our walker/swimmer, who after months of effective walking may by now feel highly committed to brisk walking and even define herself as a "walker," intentionally disregarding the both the physical benefits of swimming and 
her knee-pain contingency condition. Note that these points also differentiate contingent backup plans from coping plans (e.g., Sniehotta, Schwarzer, Scholz, \& Schüz, 2005), which are conceptually similar to implementation intentions.

Redundant backup plans. Not every backup plan is developed with a specific marker of when it should replace a first-choice plan. For example, a student might have two means to learn German: inexpensive group courses or expensive one-on-one tutoring sessions. She chooses to enroll in the group courses as a first-choice plan, and holds tutoring as a backup. Later, her friend endorses the tutoring sessions, and after some time deliberating, she decides to switch to tutoring because it represents the better option. In this particular example, the tutoring sessions represent a redundant backup plan, an alternative means held in reserve because it may later prove more useful than the first-choice plan. In contrast to contingent backup plans, which replace a failing first-choice plan after the contingency condition (e.g., if the language student specified that she would switch to tutoring if she couldn't make simple conversation in three months), redundant backup plans replace a first-choice plan at a person's discretion, when he or she determines that the backup plan provides better chances for goal achievement. In general, then, contingent backup plans are developed and reserved to minimize potential losses, whereas redundant backup plans are developed and reserved to maximize potential gains.

How does a person judge when a redundant backup plan may maximize gains compared to a first-choice plan? Instead of establishing a contingency condition, we posit that people keep redundant backup plans activated - to varying degrees - in order to compare their potential usefulness with that of the first-choice plan. This activation can facilitate timely replacement and efficient overall goal pursuit, but could also introduce additional costs to the reserving process.

At the lowest levels of activation, reserved redundant backup plans are occasionally 
compared to active first-choice plans to ascertain which means will maximize gains for goal pursuit. These comparisons can allow for a timely choice to replace a first-choice plan; however, frequent or premature comparisons could interfere with the first-choice plan. Therefore, effective use of redundant backup plans could hinge on flexibly "shielding” (e.g., Achtziger, Gollwitzer, \& Sheeran, 2008; Shah, Friedman, \& Kruglanski, 2002) reserved means, limiting comparisons of whether the "grass is greener" on the side of the backup plan, and instead acting decisively once goal-relevant feedback (e.g., Carver \& Scheier, 1998) indicates the reserved redundant backup plan's potential to maximize gains. In terms of the language student, her redundant tutoring backup plan could interfere with her progress in the group classes if she constantly tries to imagine how much better at German she would be, if only she were enrolled in tutoring sessions.

In other words, keeping a reserved redundant backup plan highly activated may prove adaptive in some situations but maladaptive in others. When actively comparing their means, a person may pause their use of the first-choice means and return to a pre-actional mindset (e.g., Gollwitzer, Heckhausen, \& Steller, 1990) to ponder whether they are more likely to efficiently achieve their goal using their redundant backup plan. Therefore, instead of pausing to decide when to disengage from a goal after accumulated losses (termed an "action crisis;" Brandstätter, Herrmann, \& Schüler, 2013), in these situations, the person must decide whether or not to disengage from the first-choice means after accumulated evidence that the redundant backup plan may now better maximize gains towards goal achievement. Extended deliberations of this type could interfere with goal achievement.

Although reserved redundant backup plans remain activated to varying degrees to facilitate comparing means options, it is important to clearly draw a distinction between this activation and concurrently using the means. Reserved redundant backup plans are not used alongside the first- 
choice plan to achieve the goal. However, actively comparing means options could result in a person deciding to take a backup plan out of reserve and use it concurrently with the first-choice plan, rather than replacing it wholesale (as we have described the "replacing" process). For example, after comparing her German learning options after several weeks of group classes, the language student could enroll in group classes and tutoring sessions simultaneously. Although this decision can prove adaptive for some goals, it again brings about the challenges that come with using multiple means concurrently, namely, decreases in the resources and motivation necessary to persist with the first-choice plan (Huang \& Zhang, 2013).

\section{Complexity value: Calculating the true costs and benefits of backup plans}

In the prior section, we defined backup plans and their underlying developing, reserving, and replacing processes. We specified that there are two prototypical types of backup plans (contingent and redundant) that differ in their use. In this section, we provide a foundation for understanding variations in the use and usefulness of backup plans. This requires emphasizing two points. First, backup plans require additional resources compared to a single-means approach. For example, having the backup plan of composing a novel by hand (instead of on a computer) requires buying pens and a stack of notebooks. Second, backup plans introduce additional and often unpredictable costs and benefits into the goal pursuit that can lead to efficient goal success, or, in some cases, accelerated goal failure. If the novelist is easily distracted by emails or suffers from monitor-related eyestrain, writing by hand could provide benefits. However, having the option of writing by hand could distract from the novelist's commitment to writing on the computer. After switching to pen and paper, the novelist may run out of notebooks, or her editor may later have trouble reading her handwriting. Combining these two points provides the foundation for our second premise: understanding the use and usefulness 
of backup plans requires a comprehensive accounting of the additional costs and benefits that backup plans introduce relative to pursuing the same goal with a single means alone.

\section{Costs and benefits of developing backup plans}

The benefits of developing contingent and redundant backup plans are largely psychological in nature. Developing backup plans may increase a person's control expectancy (Skinner, 1996), supporting confidence in their ability to achieve meaningful personal goals through their agency (e.g., Little, Snyder, \& Wehmeyer, 2006). In addition, having backup plans may increase motivation at the onset of goals, as variety in available means has been shown to promote motivation when progress toward goal achievement is low (Etkin \& Ratner, 2012). In addition, backup plans could, in some cases, increase commitment to the first-choice plan. For example, our German-language student could consider paying the extra money for private tutoring so aversive that this backup plan increases her commitment to study in the group class. In other words, through a variety of processes, developing backup plans may provide the "boost" necessary to undertake difficult or uncertain goal pursuits.

Developing contingent and redundant backup plans can involve some unique costs and some shared costs. For both approaches, considering various equifinal means to achieve a goal, identifying potentially useful options, and choosing to reserve them requires some degree of resource expense (e.g., time, effort). In addition, developing backup plans could later decrease commitment to one's first-choice plan (Kruglanski et al., 2011). More specifically, developing contingent backup plans requires specifying contingency conditions that denote an adaptive juncture to replace failing first-choice plans. If specifying a contingency condition is straightforward (e.g., "If Plan A fails, then I will use Plan B”), developing costs are low. However, if the contingency condition criteria are less stark (e.g., "If Plan A fails like this..." or 
"If Plan A does not succeed by this date..."), specifying contingency conditions may be costlier.

Redundant backup plans also introduce unique developing costs. Instead of deciding whether or not to develop backup plans that address foreseeable contingencies, developing redundant backup plans involves selecting which means from the set of all equifinal means could later prove useful for goal pursuit. For some goals, the size of this equifinality set could be large. Identifying potentially useful redundant backup plans within this set may be a costly search for a "needle in a haystack," and could prove ultimately demotivating (e.g., Iyengar, Jiang, \& Huberman, 2004; Iyengar \& Lepper, 2000) when it is experienced as very effortful and thereby taken as an indicator of a low probability of success of reaching the goal (cf. Winkielman, Schwarz, Fazendeiro, \& Reber, 2003). Relatedly, in terms of Simon's work on satisficing (e.g., Simon, 1956), trying to find the very best "needle" in the "haystack" of possible redundant backup plan choices could lead to declines in a person's positive affect (Schwartz et al, 2002).

In circumstances in which a person achieves a goal without using the backup plan he or she developed, understanding the costs and benefits of developing backup plans are more complex. In an arguably ideal scenario-where a person's first-choice plan leads to efficient goal achievement-developing unused backup plans might be considered a prudent but unnecessary expense, an ambivalently-experienced scenario akin to paying for comprehensive health insurance but remaining healthy across the life span. However, there are other situations where developing backup plans is not necessary and could be considered an instance of misregulation or overregulation (e.g., Baumeister \& Heatherton, 1996).

\section{Costs and benefits of reserving backup plans}

Reserving contingent and redundant backup plans provide the same general benefit of increasing the number of equifinal means readily available to efficiently replace a first choice 
plan. However, this general gain should be qualified with the specific gains and losses produced through reserving with the contingent or redundant approach.

As described earlier, people keep redundant backup plans activated to assess if they will maximize gains compared to the first-choice plan. These active comparisons could provide the benefit of timely replacement of an inadequate first-choice plan, or introduce the cost of excessive comparisons of one's options, distracting resources away from the first-choice plan and undermining its chances for success. In contrast, because contingent backup plans are only activated for potential use by the contingency condition, investment in these means is limited while they remain in reserve. Thus, reserving these plans allows for focused pursuit using the first-choice plan, as well as a ready replacement should these means fail in the expected way. However, a misspecified contingency condition could introduce additional costs in goal pursuit. If the first-choice plan fails in an unanticipated way, or if a contingent backup plan is no longer suitable for achieving a goal, then a person incurs additional costs when developing new backup plans or attempting to reconfigure existing backup plans. For example, recall the earlierdescribed older adult who reserved swimming as a backup plan in case walking hurt her knees. If she instead suffers a setback in lung function, or if she indeed injures her knees but the swimming pool in her town has closed down, then her investments in developing and reserving the swimming backup plan may be wasted.

\section{Costs and benefits of replacing with backup plans}

In ideal cases, replacing an insufficient first-choice plan with a contingent or redundant backup plan provides the benefit of efficient means substitution, and ultimately of optimizing one's chances to achieve the goal. In addition, replacing with a backup plan could be experienced positively-a sense of verification that developing and reserving backup plans was 
worthwhile. Of course, replacing with either contingent or redundant backup plans can also introduce additional costs. Because backup planning involves some intentional action, extended deliberation on whether or not to replace the first-choice plan could delay progress toward the goal. In addition, replacing a first-choice plan can involve acknowledging the limitations of that plan, which for some may be aversive (e.g., Brown \& Dutton, 1995; Iles, Judge, \& Wagner, 2010) and akin to admitting failure. Moreover, replacing a first-choice plan might also be difficult because the prior investment into the original plan constitutes sunk costs. A phenomenon related to sunk costs is known as "escalation of commitment," and, in terms of backup plans, would involve a person's choice to continue using a failing first-choice plan because he or she has highly invested in it, rather than replacing the first-choice plan with a backup plan based on this alternative means' likelihood of success (e.g., Staw, 1976). Finally and most simply, replacing the original plan with a backup plan may still lead to goal failure, thus representing a fruitless resource expense.

As with developing and reserving, replacing with contingent backup plans introduces particular costs and benefits. Given the contingency condition cue, replacing with contingent backup plans can be an efficient process that maintains one's momentum in the goal pursuit. However, anticipating or experiencing the losses that define one's contingency condition could be especially emotionally (e.g., Bagozzi \& Pieters 1998; Baumgartner, Pieters, \& Bagozzi, 2008) or motivationally challenging (e.g., Higgins, 1997), thus increasing replacing costs. In terms of the older adult with the swimming backup plan, after she experiences knee discomfort, she may be distraught about her declining mobility and suffer motivational setbacks, wondering if, for instance, it is even worth the effort to try swimming instead. 
In terms of redundant backup plans, correctly choosing to replace a first-choice plan can maximize gains through more efficient goal achievement. However, the losses that redundant backup plans may introduce are also based in their gains-maximizing nature. It may be less likely for a first-choice plan to be extinguished as an option after it is replaced, because it could later maximize gains compared to the former backup plan. In other words, for some redundant backup plans, the replaced first-choice plan may be reserved for potential later use, reintroducing comparison costs in a recapitulated reserving process.

\section{Complexity value}

In review, people make backup plans in an attempt to manage uncertainty and improve their chances for goal achievement. These backup plans introduce additional costs and benefits during the developing, reserving, and replacing processes. The additional costs and benefits are themselves uncertain, and therefore introduce greater complexity into the goal pursuit when compared to the relative simplicity of pursuing a goal with a single means. Here we return to our central question: When do backup plans serve as a prudent safety net supporting efficient goal pursuit, and when are they an unnecessary expense that can interfere with a first-choice plan and compromise goal striving?

We posit that in order to grasp the true adaptiveness (or maladaptiveness) of having backup plans, we must compare their utility to that of the "nested" option of pursuing the same goal with the same first-choice plan alone. For example, we can only truly understand if our hapless photographer's choice to carry three backup lenses was adaptive when we compare this chosen approach to the hypothetical approach of his potentially having carried only a single lens. We term the current difference between the benefit/cost ratios of a backup plan approach and a single means approach complexity value. Thus, the basic formula for calculating complexity value is: 
$\left(\frac{\text { Benefits of backup plan approach }}{\text { Costs of backup plan approach }}\right)-\left(\frac{\text { Benefits of single-means approach }}{\text { Costs of single-means approach }}\right)$. What constitutes a cost and a benefit can only be determined in relation to the goal at hand. At a global level, the costs and benefits used to calculate complexity value are measured in terms of aggregated practical (e.g., time, money) and psychological (e.g., motivation, effort) goal-relevant resources. ${ }^{2}$

From where does the "complexity" in complexity value arise? Consistent with the basic thesis of this article, we maintain that having a backup plan changes the way a person pursues a goal with their first-choice plan, and their likelihood of achieving the goal altogether, even if the backup plan is not currently or ever used. In other words, the relative "permeability" of reserved backup plans can result in their benefits and costs being "counted twice:" first, in terms of their own impact (e.g., the time it takes to develop a backup plan), and second in terms of their impact on the active first-choice plan (e.g., motivational challenges; the decreased effectiveness of an under-invested first-choice plan).

To make this concept more concrete, recall again the introductory example of the photographer taking additional lenses up the hill to the photo location. Every minute he spends carrying his extra lenses (a cost of reserving his backup plans) could have been spent discerning which of these lenses to use at the vantage point, or, alternatively, framing the perfect photo with his single lens, if he had opted for the simpler single-means approach. The cost of these minutes for few tangible benefits decreased the complexity value of the backup plan approach. Thus, counter to the photographer's expectations, having backup plans interfered so much with the first-choice means that it led to goal failure.

Computing complexity value, therefore, is a dynamic accounting of the effects of pursuing a goal with a backup plan. In ideal circumstances, reserved backup plans increase the value of the active first-choice plan (e.g., by increasing confidence) for limited costs, or efficiently replace a 
failing first-choice means, resulting in a positive complexity value (i.e., better value from more complexity). We argue that a negative complexity value (i.e., worse value from more complexity) primarily comes about not because backup plans "don’t help enough," but rather when the additional motivational and resource-based costs required to use backup plans results in the decreased value of the first-choice plan.

Complexity value as momentary and fluctuating. It is important to stipulate that complexity value refers to differences between the current benefit/cost ratio of pursuing a goal with versus without a backup plan. Said differently, complexity value does not include the potential future benefits of a backup plans, nor does it include the potential costs associated with replacing a first-choice plan. Complexity value refers only to those additional costs or benefits that are currently experienced as a result of adopting a backup plan. Therefore, complexity value fluctuates across goal pursuit, and often remains negative, until one perhaps makes an adaptive choice to replace an underperforming first-choice plan (at which point the complexity value increases and may, in some cases, becomes positive).

Figure 1 is an illustration of the complexity value for our example of the German language student. In this basic example, the benefit-cost ratio of the single-means approach remains positive and consistent across goal pursuit. As stated earlier, not every single-means approach has a consistent benefit-cost ratio, nor is the value of every single-means approach positive. We present a consistent, positive value for the single-means approach in this figure simply for illustrative purposes.

Point A in Figure 1 represents a decrease in complexity value for developing the tutoring backup plan. Here, the student spent additional time inquiring about tutoring hours, for instance. Point B represents an increase in complexity value due to psychological benefits of having two 
German learning means available. Point $\mathrm{C}$ depicts decreasing complexity value, when the student is actively comparing the group classes and the reserved tutoring classes. Finally, point D depicts replacing costs - switching to tutoring required, in this case, recalibrating her schedule to account for the additional tutoring homework. In this example, replacing the first-choice plan with a backup plan was an adaptive choice. After recalibrating for the new means, the value of having a backup plan gradually increases and, at the goal's terminus, is greater than that of the single-means approach. Of course, points A, B, C, and D can vary widely across goal pursuits in terms of their presence, slope, or magnitude. For example, imagine if the first-choice plan (group class) value increases over time, representing a practice or acclimation effect. In that case, the choice to replace with the tutoring classes may prove less adaptive.

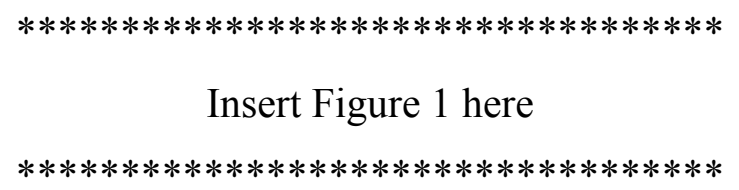

Figure 2 represents a potentially adaptive use of a contingent backup plan - an extension of the older adult with a fitness maintenance goal and the walking / swimming means. There are numerous differences between Figures 1 and 2. For example, note that that the complexity value in point $\mathrm{A}$ in Figure 2 is lower than those at point $\mathrm{A}$ in Figure 1. In this particular example, developing the contingent swimming backup plan was costly. The older adult consulted with her doctor, who recommended swimming as a backup plan, and then she called several local swimming pools to compare "Senior discounts" on their membership fees. Note also that the complexity value at point $\mathrm{C}$ in Figure 2 is higher than the complexity value at the same point in Figure 1, and remains at a relatively steady level until the older adult nears the contingency condition (sore knees). Reserving contingent backup plans requires fewer resources than reserving redundant backup plans. In terms of this example, the older adult only begins to 
consider the swimming backup plan when her knees feel "stiff," a typical precursor to her soreness.

The vertical line represents the sore-knee contingency condition, and the older adult's choice to replace walking with swimming. First, note here that the benefit/cost ratio of the single-means approach drops precipitously - walking is no longer a viable means. Second, note the decrease in complexity value beginning at point $\mathrm{D}$, which represent the emotionally aversive effects of passing the contingency condition, as well as the cost of recalibrating for the backup plan. In this case, the older adult is disappointed about her knees, and in order replace with her swimming means, must purchase goggles and a swimsuit. Despite these additional costs, next observe the relatively quick transition to steady complexity value after point $\mathrm{D}$, which illustrates contingent backup plans' prototypically efficient replacing process. Finally, note that the older adult is able to complete her goal with the backup plan, but does so less efficiently than if she were to have been hypothetically able to continue using her walking means. Here, imagine that the older adult must drive half an hour to the swimming pool, reducing her exercise time and motivation.

$* * * * * * * * * * * * * * * * * * * * * * * * * * * * * * * * * *$

Insert Figure 2 here

$* * * * * * * * * * * * * * * * * * * * * * * * * * * * * * * * * *$

Terminal complexity value as a metric for backup plan utility. Under which conditions are backup plans are useful? From an empirical standpoint, retrospectively assessing terminal complexity value, or the difference in value between the backup means and single-means approaches at the conclusion of a goal pursuit, can be a convenient metric for researchers to assess whether having a backup plan was an adaptive choice for this particular goal. If terminal complexity value is positive (that is, when the benefit/cost ratio of having backup plans exceeds that of an approach without one), then backup planning was clearly adaptive. However, if 
terminal complexity value was lower than the costs of goal failure, backup planning was clearly maladaptive. In other words, resources are wasted if maintaining backup plans costs more failing at the goal itself. Finally, when terminal complexity value is higher than goal failure but lower than the single-means approach, then the choice to backup plan was less efficient than a singlemeans approach. As we will describe in the next section, people may vary in the extent to which they accept decreased complexity value in exchange for increased perceived likelihood for success across different goals and contexts.

\section{Complexity value estimation and regulation: A key for understanding the use and usefulness of backup plans}

Assessing terminal complexity value retrospectively may be a valuable metric for estimating whether a study participant's use of backup plans was adaptive. However, this approach does not shed light on who uses backup plans or the circumstances under which people typically use backup plans. Still, terminal complexity value can provide some insight. We posit that people are likely to use their estimates of terminal complexity value as a heuristic for whether backup plans are a wise investment. Broadly consistent with expectancy-value models (e.g., Eccles \& Wigfield, 2002), if the projected terminal complexity value is positive, or within one's acceptable threshold of decreased complexity value for increased likelihood of success, we posit that people tend to develop backup plans. This represents the first part of our third premise.

For a concrete example, we can return to the opening story of the photographer. In choosing to pack (develop) and carry (reserve) the backup lenses, the photographer was willing to accept projected declines in terminal complexity value in order to improve his overall chances of taking the perfect picture. His incorrect estimation - "Even though they are heavy, it's good to carry these alternate lenses - now I'll definitely get the perfect picture" - is a reflection of the terminal 
complexity value heuristic. Using this heuristic lead the photographer to make a choice to backup plan that ultimately lead to goal failure.

Consistent with the concept of subjective expected utility (e.g., Savage, 1954) in decision theory, there are factors at the individual, contextual, and goal-level that influence the way a person uses the terminal complexity value heuristic. The photographer may have packed extra lenses due to some combination of a lack of photographic experience (individual characteristic), the difficulty of capturing a perfect sunset photo (goal characteristic), and the general unpredictability of the environmental conditions at the vantage point (contextual characteristic). However, a different photographer who is both highly experienced and taking a more predictable, simple photo may use the terminal complexity value heuristic to assess that she does not need to pack additional backup lenses. This photographer may think "I've taken thousands of portraits in the park with this one lens. I am quite sure how this will go. Why pack a backup lens when it probably won't be worth lugging the extra weight around?"

It is important to note that there exist a host of specific subjective or idiosyncratic factors that may influence the way a person uses the terminal complexity value heuristic. For example, at the individual level, people who are more conscientious (e.g., Roberts, Jackson, Fayard, Edmonds, \& Meints, 2009), more ruminative (e.g., Schultheiss, Jones, Davis, \& Kley, 2008), or more rigid (e.g., Chess \& Thomas, 1999) may be willing to accept decreased complexity value in exchange for increased perceived likelihood for success. In addition, those with higher levels of practical intelligence (e.g., Sternberg et al, 2000; Wagner \& Sternberg, 1985) in a particular domain may be better at estimating terminal complexity value, and thus may be more or less likely to develop backup plans, depending on these estimations.

At the level of the goals themselves, decreased terminal complexity value may be perceived 
as more acceptable for unpredictable, important goal pursuits, such as the university application process or the school-to-work transition (Freund, Weiss, \& Wiese, 2013). In addition, the relative cost of developing backup plans likely plays a role. For instance, packing an extra pair of socks in a roomy suitcase is likely a common backup plan for comfort in case of rain - the projected decreases in terminal complexity value of the having the additional pair of socks is negligible. In addition, at the contextual level, there may be social or cultural differences in the way the terminal complexity value heuristic is used, as has been demonstrated in other goal-related domains (e.g., Grob, Little, Wanner, Wearing, \& Euronet, 1996; Levesque, Zuehlke, Stanek, \& Ryan, 2004). Each of these factors is worthy of future inquiry but goes beyond the scope of this article.

\section{Terminal complexity value as a potentially problematic heuristic for backup plan use}

Taken together, we posit that people use the projected terminal complexity value as a heuristic for the decision to make backup plans. That is, people make backup plans if their best guess is that it will be "worth it in the end." The way this heuristic is used varies as a function of individual, contextual, and goal-related factors. For example, some people may sketch out a "pros and cons" lists when making the decision to develop a backup plan, whereas others may decide more intuitively, perhaps even based on emotional cues without any deliberation (e.g., Mellers, 2000).

Note, however, that we do not suggest that people typically calculate (or are even able to accurately estimate) fluctuations in complexity value across the entire goal pursuit when making this decision, and "aye, there's the rub," so to speak. In fact, we posit that people might systematically overlook and/or fail to accurately predict the costs that backup plans introduce during the goal pursuit before they are used, as these reserving costs are not tangible and not 
easy to project given the complexity that backup plans introduce into a goal pursuit. This can prove problematic.

Our photographer again provides an excellent example. From the perspective of the projected terminal complexity value heuristic, the photographer packed each of the lenses because he perceived that their costs (i.e., packing each in the bag) provided an acceptable benefit for the sunset photo (i.e., having the perfect lens available). However, he failed to account for the how the reserving and replacing costs (i.e., the weight of bags slowing progress, and deliberating which lens to actually use) would affect the goal pursuit. Even if he had expected that carrying backup lenses might slow him down to some degree, he could not accurately estimate how much they would interfere with his first ascent to the vantage point.

In other words, using the projected terminal complexity value to decide whether or not to use backup plans can potentially prove maladaptive. Even if the terminal complexity value proves to be positive, shouldering the costs incurred when pursuing the goal has the potential to jeopardize its successful completion. These "overlooked" decreases in complexity value can be considered both in terms of goal-relevant resources. The resources used to support a backup plan could have been allocated to the first-choice plan had one adopted the simpler single-means approach. In the above example, the time spent packing the camera lenses and carrying their extra weight came at the expense of arriving to the vantage point with a single lens and on time. “Overlooked" complexity value declines during goal pursuit can also undermine a person's motivation to continue with the goal, even if they objectively retain goal-relevant resources. It could be demotivating when, at an impasse, a person must deliberate between replacing an underperforming, yet predictable first-choice plan with an uncertain backup plan. This might be due to the fact that each potential alternative to the selected means instigates comparison 
processes calling into doubt the instrumentality of the chosen means (c.f., the negative effects of choosing from a large array of alternatives compared to a small one; Iyengar \& Lepper, 2000; Schwartz, 2004; Schwartz et al, 2002).

As we noted earlier, despite these potential issues, many cases of backup planning include periods when a person accepts the negative complexity value (or greater potential variance in complexity value) in return for increased likelihood for goal achievement. As these periods are almost unavoidable, the declines in complexity value that are introduced by backup plans before they are used must be regulated to ensure that their adaptive use. This represents the second portion of our third premise. At a basic level, this regulation involves attempting to approach the adaptive "ceiling" where the terminal complexity value is positive, and avoid the maladaptive "floor" where the costs introduced by backup plans are greater than the cost of failure. However, regulating complexity value is itself more complex than approaching or avoiding these basic markers.

\section{Understanding adaptive backup plan use through the regulation of complexity value}

We argue that a person's approach to regulating complexity value - or alternatively, how a person regulates the effects of their backup plans on their goal pursuit - is key for understanding variations in the usefulness of backup plans. In the first section of this article, we posited that there are two types of backup plans: contingent and redundant. In this section, we recast contingent and redundant backup planning as two prototypical approaches to regulating complexity value. Before doing so, however, we briefly describe regulation in terms of complexity value.

Looking back at Figures 1 and 2 provides a simple way to understand regulating complexity value. In terms of these visualizations, regulating complexity value involves a person's attempts 
to minimize the "negative amplitude" of the backup plan approach curve across the goal pursuit. Note that the negative amplitude of the backup plan approach curve in the Figure 2 is smaller than that of the backup plan approach curve in Figure 1. The older adult's fitness goal (Figure 2) illustrates a steady, yet perhaps overall inefficient goal pursuit, whereas the language learning (Figure 1) displays a riskier "boom or bust" approach.

Of course, rather than just illustrations of curves, Figure 1 displays a redundant approach and Figure 2 displays a contingent approach. In other words, we can recast our two "types" of backup plans from Section 1 into two prototypical contingent and redundant approaches to regulating complexity value. The contingent approach to complexity value regulation attempts to minimize the costs of backup planning across the goal pursuit by selectively focusing on one's first-choice means until nearing or meeting the contingency condition. Alternatively, the redundant regulatory approach attempts to maximize the potential benefits of backup planning by keeping several backup plans available for timely replacement.

\section{The sample case of hypothetical age-related differences in the use and usefulness of backup plans}

What characteristics are associated with the decision to use the contingent or redundant approach? For our fourth core premise, we posit that there are a variety of individual, contextual, and goal-related factors that influence the estimation and regulation of complexity value, and thus the use and usefulness of backup plans. Unfortunately, exploring each of these factors is outside the scope of this article. However, notably, the contingent approach is likely not adaptive (or perhaps possible) if a person cannot accurately predict or cannot foresee the contingency condition. For example, if the older adult cannot foresee a possible knee injury, then it is unlikely that she develops the backup plan of swimming - an exercise that is gentler on her knees. 
Likewise, given the large potential variations in complexity value, the redundant approach to regulation is likely not adaptive (or possible) in goal pursuits where a person has few resources. For example, the language learner should not reserve and compare the benefits of backup tutoring courses if she could never afford them.

Although we cannot describe here variations in the use and usefulness of backup plans for every person and every goal, we can provide a prototypical example our central premises about backup plans and complexity value. In this section, using the life-span developmental perspective (Baltes, 1987) as a foundation, we present our hypotheses for age-related differences in the use and utility of backup plans.

In general, successful aging entails maximizing potential gains while minimizing potential losses (Baltes \& Baltes, 1990; Freund, Nikitin, \& Riediger, 2012). Across the life span, people must recalibrate their actions to reflect variations in their resources (Staudinger, Marsiske, \& Baltes, 1995) and in their level of experience of expertise with certain goal pursuits. We argue that this shift in adaptive behavior also includes shifts in backup planning. In short, we propose two general hypotheses. First, we expect that older adults are more likely to develop backup plans than younger adults. Second, we expect that when younger adults do make backup plans, they tend to adopt the redundant approach to regulation, whereas older adults tend to adopt the contingent approach. Below, we begin by providing support for our hypotheses by briefly reviewing the bases of the life-span developmental approach.

Life-span developmental theory. The core concept in life-span developmental psychology is the multidirectionality of human ontogeny; that is, that development is characterized by trajectories of growth as well as trajectories of decline (Baltes, 1997). Although both gains and losses are always present across the life span, younger adulthood is prototypically a period of a 
greater share of gains, while older adulthood is a period with an increasing share of losses (Heckhausen, Dixon, \& Baltes, 1989; Mustafic \& Freund, 2012). The dynamic ratio of gains and losses influences the content and number of goals that people pursue. Younger adults, often flush with resources and in the process of "becoming" (Raynor, 1981), can broadly invest in a variety of goals as "promising leads" for sustained positive development. Older adults, often facing mounting losses, selectively invest their remaining resources primarily into those goals that are personally or emotionally meaningful (e.g., Brandtstädter, Rothermund, Kranz, \& Kühn, 2010; Carstensen, Isaacowitz, \& Charles, 1999; Freund \& Ritter, 2014).

Age-related changes in the ratio of gains and losses also influence the adaptiveness of one's means. In other words, successful development across the life span requires using the selfregulatory actions that maximize gains during periods of growth and, in turn, using the selfregulatory actions that minimize losses during periods of decline (Freund \& Ebner, 2005; Staudinger et al., 1995). For example, research using the SOC model indicated that older adults (i.e., those 65 years and older) typically benefit from engaging goals with loss-minimizing compensatory actions, while younger adults typically benefit from using gains-maximizing optimization actions (Ebner, Freund, \& Baltes, 2006; Freund, 2006). Backup planning, however, is comprised of a diverse collection of self-regulatory processes that can satisfy both lossminimizing and gains-maximizing motivations. In order to be adaptive, therefore, backup plans must not only address the anticipated trajectories of gains and losses in one's goal pursuit, but also address the broader trajectories of gains and losses that an individual experiences as a function of his or her age (Mustafic \& Freund, 2012).

Taken together, the dynamic ratio of gains and losses across the life span serve as the basis for our hypothesis regarding age-related differences in the use and usefulness of backup plans. 
We elaborate on these hypotheses below.

\section{Hypothesis 1: Older adults are more likely to use backup plans than younger adults}

Our first hypothesis is that older adults are more likely to develop backup plans than younger adults. This hypothesis may seem counterintuitive. Older adults are faced with declines in resources, and backup plans can introduce additional and unpredictable costs into a goal pursuit, compared to using a single means. Resource-rich younger adults, alternatively, could invest their surplus resources in a range of backup plans, attempting to ensure their success in a goal. Although younger adults certainly use backup plans, we argue older adults' declining resources and resulting selectivity in goal pursuits underlies their prototypically greater backup plan use.

Declining resources affect the way older adults make deliberative and affective-based decisions (Peters, Hess, Västfjäll, \& Auman, 2007), including those regarding goals. Faced with declines in resources, older adults typically disengage from less meaningful goals (e.g., Dunne, Wrosch, \& Miller, 2011; Wrosch, Bauer, \& Scheier, 2005) and aim to focus more on goals that are related to life domains they consider particularly important (Riediger \& Freund, 2006). Maintaining functioning or minimizing losses in these remaining important goals becomes the central motivation of older adults' self-regulative efforts (Freund \& Riediger, 2001). Failing to achieve these important goals can have adverse effects, as older adults have a declining number of opportunities to select and achieve new goals due to age norms for appropriate behavior, societal support constraints, and a shorter remaining lifetime (Baltes, Reese, \& Nesselroade, 1988). In sum, when it comes to an older adult's adaptive development, "failure is not an option." For this reason, Depping and Freund (2011) have argued that older adults might be more sensitive to potential losses when making decisions. This higher sensitivity to potential losses 
might lead older adults to be more likely to develop the safety-net of backup plans than younger adults. Note, however, that a meta-analysis on age and risk taking does not suggest that older adults are generally more risk avoidant (Mata, Josef, Saminez-Larkin, \& Hertwig, 2011). Rolison, Hanoch, Wood, and Liu (2013) found that risk taking is domain specific and multidirectional (i.e., follows different age trajectories). In the domain that is most clearly affected by age-related declines, the health domain, Rolison et al. found a linear decline in risk taking across adulthood. Thus, we expect older adults to be more likely to develop backup plans because they are willing to accept some declines in complexity value in exchange for increased likelihood of goal achievement, especially when repairing failure would be highly costly or in domains where older adults experience declines.

Younger adults certainly also use backup plans to manage uncertainty and attempt to optimize their chances of achieving their important goals. However, given their relatively greater developmental plasticity (e.g., Lerner, 1984), failure in any one goal does not necessarily have a permanent, adverse effect on their life course. In fact, failure can provide younger adults with a chance to adaptively disengage from blocked goals (Tomasik \& Salmela-Aro, 2012) and redirect their developmental trajectories toward a concurrent ends that affords maximal gains. In addition, with greater resources, younger adults can afford to be less selective with their goal investments, pursuing multiple ends simultaneously. The additional costs introduced by backup planning in one goal may be more efficiently invested in one or more of these alternate concurrent pursuits. In sum, investing resources in backup plans may be less likely for younger adults, who can pursue multiple goals concurrently and more commonly experience gains after failure, as captured by the proverb "When one door closes, another door opens."

\section{Hypothesis 2: Older adults are more likely adopt the contingent approach, but younger}




\section{adults are more likely to adopt the redundant approach}

Our second hypothesis is that older adults are more likely to take the contingent approach to regulating complexity value, while younger adults are more likely to take the redundant approach. As mentioned above, older adults should be more likely to accept some declines in complexity value to minimize their chances of failure in the goal. Although older adults might be more likely to adopt some declines in complexity value, their limited resources should also result in stronger attempts to avoid unnecessary costs. In addition, older adults' greater accumulated experience with setting and pursuing personal goals may allow for their ability to better foresee possible contingency conditions, making such an approach more feasible. The contingent approach, which more tightly regulates complexity value, is also consistent with older adults' goal-related orientation toward resource maintenance or loss-minimization (e.g., Ebner, et al, 2006). Finally, a focus on tightly regulating complexity value across the goal pursuit is consistent with older adults' tendency to focus on the process of reaching a goal (i.e., "the journey") instead of on its outcome (i.e., "the destination;” Freund, Hennecke, \& Riediger, 2010). For these reasons, we hypothesize that complexity value regulation by older adults prototypically involves adopting a contingent approach.

Younger adults likely take a different approach to regulating complexity value. Clearly, successfully achieving some goals can be an important predictor of long-term success (e.g., earning a university degree). However, younger adults generally have the time and resources to better bounce back from and repair failures (Baltes, 1987). Therefore, the maladaptive "floor" for younger adults' backup planning is higher, making backup planning somewhat less likely to be an adaptive use of resources. However, when younger adults do use backup plans, they are better able to shoulder decreases in complexity value, given their greater resource access. Moreover, 
given their orientation towards maximizing gains and achieving specific goal outcomes, some younger adults may be motivated to accept great additional costs from backup plans in order manage uncertainty and ensure goal achievement. In short, adaptive complexity value regulation for younger adults may prototypically involve using the redundant approach, which involves accepting larger decreases in complexity value during the goal pursuit in order optimize chances for maximum gains. In addition, compared to more-experienced older adults, younger adults may have a narrower behavioral repertoire, and less certainty about which means are most instrumental for a specific goal. Therefore, younger adults may develop several redundant backup plans in the hopes that one may later prove useful.

\section{Outlook}

Our aim for this article was to shed light on a ubiquitous, yet-understudied self-regulative approach to optimizing one's chances to achieve a goal: backup plans. The basic thesis of this article is that having a backup plan influences how a person pursues a goal, as well as the likelihood of achieving that goal, even if the backup plan is not currently or ever used. Despite the notion that backup plans represent a prudent "safety net," the effects of backup plans on goal pursuit can also be negative. Empirical work is needed to test under which conditions backup planning increases the chances of goal achievement and under which it may undermine successful goal pursuit. Moreover, the concept of complexity value over the course of goal pursuit will help to determine success not only in terms of goal achievement but also in terms of the additional costs and benefits of backup planning over time.

With regard to age-related differences in the adaptiveness of backup planning, certain global trends such as increased longevity may emphasize the role of backup planning may play in optimizing chances for goal achievement in old age. For example, as the length of the life span 
increases across much of the world (e.g., Vaupel, 2010), older adults are more likely faced with "the incomplete architecture of human ontogeny" (Baltes, 1997), that is, insufficient societal resources to counteract the declines in their personal resources. As such, self-regulatory skills are especially important for the functioning and development of older adults (e.g., Freund et al., 2009; Wrosch \& Freund, 2001). Thus, efficient backup planning may be particularly adaptive for older adults in the years to come.

Similarly, global economic trends may underscore the importance of backup planning. For example, globalization-related social and economic change, often been suggested as an important influence on various developmental outcomes (e.g., Larson \& Wilson, 2004; Tomasik \& Silbereisen, 2012), can result in rapid changes in fortune for certain industries, occupations, or geopolitical regions. Since the vast majority of individuals have little control over the direction of these trends, pursuing career-oriented goals while reserving backup plans is likely an adaptive approach, and may become more so in the years ahead.

The concept of complexity value may also be useful in disciplines other than psychology. For example, complexity value could represent a useful lens though which economists could assess the utility of a firm's or nation's contingency plans or behavioral economists could assess complex instances of decision-making. At a more abstract level, complexity value could be applied biological research, shedding light on the presence or absence of backup systems in the human body. In addition, researchers with an evolutionary focus could consider an organism's ability to regulate complexity value as an indication of backup planning being an "evolved" selfregulatory process that increases chances for achieving goals, accumulating more resources, and enhancing the likelihood of survival and procreation.

To summarize, backup plans represent an understudied domain worthy of future inquiry. 
Future investigations into backup planning might offer new insight into how people pursue goals, explain individual variation in the success of these goal pursuits, and, thereby, also inform interventions that optimize goal strivings. 


\section{References}

Achtziger, A., Gollwitzer, P. M., \& Sheeran, P. (2008). Implementation intentions and shielding goal striving from unwanted thoughts and feelings. Personality and Social Psychology Bulletin, 3, 381-393. doi:10.1177/0146167207311201

Bagozzi, R. P., \& Pieters, R. (1998). Goal-directed emotions. Cognition \& Emotion, 12(1), 1-26. doi:10.1080/026999398379754

Baltes, P. B. (1987). Theoretical propositions of life-span developmental psychology: On the dynamics between growth and decline. Developmental Psychology, 23, 611-626. doi:10.1037/0012-1649.23.5.611

Baltes, P. B. (1997). On the incomplete architecture of human ontogeny: Selection, optimization, and compensation as foundation of developmental theory. American Psychologist, 52, 366-380. doi:10.1037/0003-066X.52.4.366

Baltes, P. B., \& Baltes, M. M. (1990). Psychological perspectives on successful aging: The model of selective optimization with compensation. In P. B. Baltes \& M. M. Baltes (Eds.), Successful aging: Perspectives from the behavioral sciences (pp. 1-34). New York: Cambridge University Press. doi:10.1017/CBO9780511665684.003

Baltes, P. B., Reese, H. W., \& Nesselroade, J. R. (1988). Life-span developmental psychology: An introduction to research methods. Hillsdale, NJ: Erlbaum.

Baltes, P. B., Staudinger, U. M., \& Lindenberger, U. (1999). Lifespan psychology: Theory and application to intellectual functioning. Annual Review of Psychology, 50, 471-507. doi:0.1146/annurev.psych.50.1.471

Bargh, J. A., \& Chartrand, T. L. (1999). The unbearable automaticity of being. American Psychologist, 54, 462-479. doi:10.1037/0003-066X.54.7.462 
Bargh, J. A., Schwader, K. L., Hailey, S. E., Dyer, R. L., \& Boothby, E. J. (2012). Automaticity in social-cognitive processes. Trends in Cognitive Sciences, 16, 593-605. doi:10.1016/j.tics.2012.10.002

Baumeister, R.F., \& Heatherton, T.F. (1996). Self-regulation failure: An overview. Psychological Inquiry, 7, 1-15. doi:10.1207/s15327965pli0701_1

Baumgartner, H., Pieters, R., \& Bagozzi, R. P. (2008). Future-oriented emotions: conceptualization and behavioral effects. European Journal of Social Psychology, 38, 685-696. doi:10.1002/ejsp.467

Bertalanffy, L. V. (1968). General system theory: Foundations, development, applications. New York: Braziller.

Brandtstädter, J., Rothermund, K., Kranz, D., \& Kühn, W. (2010). Final decentrations: Personal goals, rationality perspectives, and the awareness of life's finitude. European Psychologist, 15, 152-163. doi:10.1027/1016-9040/a000019

Brandstätter, V., Herrmann, M., \& Schüler, J. (2013). The struggle of giving up personal goals: Affective, physiological, and cognitive consequences of an action crisis. Personality and Social Psychology Bulletin, 39, 1668-82. doi:10.1177/0146167213500151

Brown, J. D., \& Dutton, K. A. (1995). The thrill of victory, the complexity of defeat: Self-esteem and people's emotional reactions to success and failure. Journal of Personality and Social Psychology, 68, 712-722. doi:10.1037/0022-3514.68.4.712

Carstensen, L. L., Isaacowitz, D. M., \& Charles, S. T. (1999). Taking time seriously: A theory of socioemotional selectivity. American Psychologist, 54, 165-181.

doi:10.1037/0003066X.54.3.165 
Carver, C. S., \& Scheier, M. F. (1998). On the self-regulation of behavior. New York: Cambridge University Press.

Chess, S., \& Thomas, A. (1999). Goodness of fit: Clinical applications, from infancy through adult life. Philadelphia: Taylor \& Francis.

Depping, M. K. \& Freund, A. M. (2011). Normal aging and decision making: The role of motivation. Human Development, 54, 349-367. doi:10.1159/000334396

Dunne, E., Wrosch, C., \& Miller, G. E. (2011). Goal disengagement, functional disability, and depressive symptoms in old age. Health Psychology, 30, 763-770. doi:10.1037/a0024019

Dweck, C. S., \& Leggett, E. L. (1988). A social-cognitive approach to motivation and personality. Psychological Review, 95, 256-273.

Ebner, N. C., Freund, A. M., \& Baltes, P. B. (2006). Developmental changes in personal goal orientation from young to late adulthood: from striving for gains to maintenance and prevention of losses. Psychology and Aging, 21, 664-67. doi:10.1037/0882-7974.21.4.664

Eccles, J. S., \& Wigfield, A. (2002). Motivational beliefs, values, and goals. Annual Review of Psychology, 53, 109-132. doi: 10.1146/annurev.psych.53.100901.135153

Etkin, J., \& Ratner, R. K. (2012). The dynamic impact of variety among means on motivation. Journal of Consumer Research, 38, 1076-1092.

Ford, D. H., \& Lerner, R. M. (1992). Developmental systems theory: An integrative approach. Newberry Park, CA: Sage.

Freund, A. M. (2006). Age-differential motivational consequences of optimization versus compensation focus in younger and older adults. Psychology and Aging, 21, 240-252. doi: $10.1037 / 0882-7974.21 .2 .240$

Freund, A. M. (2008). Successful aging as management of resources: The role of selection, 
optimization, and compensation. Research in Human Development, 5, 94-106. doi:10.1080/15427600802034827

Freund, A. M., \& Baltes, P. B. (2002). Life-management strategies of selection, optimization and compensation: Measurement by self-report and construct validity. Journal of Personality and Social Psychology, 82, 642-662. doi:10.1037/0022-3514.82.4.642

Freund, A. M., \& Ebner, N. C. (2005). The aging self: Shifting from promoting gains to balancing losses. In W. Greve, K. Rothermund, \& D. Wentura (Eds). The adaptive self: Personal continuity and intentional self-development (pp. 185-202). Ashland, OH: Hogrefe \& Huber.

Freund, A. M. Hennecke, M., \& Riediger, M. (2010). Age-related differences in outcome and process goal focus. European Journal of Developmental Psychology, 7, 198-222. doi: $80 / 17405620801969585$

Freund, A. M., \& Riediger, M. (2001). What I have and what I do: The role of resource loss and gain throughout life. Applied Psychology: An International Review, 50, 370 -380.

Freund, A. M., \& Riediger, M. (2006). Goals as building blocks of personality and development in adulthood. In D. K. Mroczek \& T. D. Little (Eds.) Handbook of personality development (pp. 353-372). Mahwah, NJ: Erlbaum.

Freund, A. M., Nikitin, J., \& Riediger, M. (2012). Successful aging. In R. M. Lerner, A. Easterbrooks, \& J. Mistry (Eds.), Handbook of psychology, Vol. 6. Developmental psychology (2 $2^{\text {nd }}$ ed.). New York: Wiley. doi:10.1002/0471264385.wei0625

Freund, A. M. \& Ritter, J. O. (2014). Values across adulthood: A neglected developmental construct guiding thought and action over time. In P. Verhaeghen \& C. Hertzog (Eds.), The Oxford handbook of emotion, social cognition, and everyday problem solving during 
adulthood. New York: Oxford University Press. doi:

10.1093/oxfordhb/9780199899463.013.017

Freund, A. M., Weiss, D., \& Wiese, B. S. (2013). Graduating from high school: The role of gender-related attitudes, attributes, and motives for a central transition in late adolescence. European Journal of Developmental Psychology, 10, 580-596. doi:0.1080/17405629.2013.77250

Gollwitzer, P. M. (1993). Goal achievement: The role of intentions. European Review of Social Psychology, 4, 141-185. doi:10.1080/14792779343000059

Gollwitzer, P. M. (1999). Implementation intentions: strong effects of simple plans. American Psychologist, 54, 493-503. doi:10.1037/0003-066X.54.7.493

Gollwitzer, P. M., Heckhausen, H., \& Steller, B. (1990). Deliberative and implemental mindsets: Cognitive tuning toward congruous thoughts and information. Journal of Personality and Social Psychology, 59, 1119 -1127.

Grob, A., Little, T. D., Wanner, B., Wearing, A. J., \& Euronet. (1996). Adolescents' well-being and perceived control across 14 sociocultural contexts. Journal of Personality and Social Psychology, 71, 785-795. doi:10.1037/0022-3514.71.4.785

Heckhausen, J. (1999). Developmental regulation in adulthood: Age-normative and sociostructural constraints as adaptive challenges. New York: Cambridge University Press

Heckhausen, J., Dixon, R. A., \& Baltes, P. B. (1989). Gains and losses in development throughout adulthood as perceived by different adult age groups. Developmental Psychology, 25, 109-121. doi:10.1037/0012-1649.25.1.109 
Higgins, E. T. (1997). Beyond pleasure and pain. American Psychologist, 52, 1280-1300. doi:10.1037/0003-066X.52.12.1280

Huang, S. C., \& Zhang, Y. (2013). All roads lead to Rome: The impact of multiple attainment means on motivation. Journal of Personality and Social Psychology, 104, 236-248. doi:10.1037/a0031039

Iles, R., Judge, T. A., \& Wagner, D. T. (2010). The influence of cognitive and affective reactions to feedback on subsequent goals: Role of behavioral inhibition/activation. European Psychologist, 15, 121-131. doi:10.1027/1016-9040/a000011

Iyengar, S. S., Jiang, W., \& Huberman, G. (2004). How much choice is too much: Determinants of individual contribution in $401 \mathrm{k}$ retirement plans. In O. S. Mitchell, \& S. Utkus (Eds.), Pension design and structure: New lessons from behavioral finance (pp. 83-97). Oxford: Oxford University Press.

Iyengar, S. S., \& Lepper, M. R. (2000). When choice is demotivating: Can one desire too much of a good thing? Journal of Personality and Social Psychology, 79 (6), 995-1006. doi: $10.1037 / / 0022-3514.79 .6 .995$

Kruglanski, A. W., Pierro, A., \& Sheveland, A. (2011). How many roads lead to Rome? Equifinality set-size and commitment to goals and means. European Journal of Social Psychology, 41, 344-352. doi:10.1002/ejsp.780

Kruglanski, A. W., Shah, J. Y., Fishbach, A., Friedman, R., \& Chun, W. Y. (2002). A theory of goal systems. In M. P. Zanna (Ed.) Advances in experimental social psychology, 34, (pp. 331-378), San Diego: Academic Press.

Labroo, A. A., \& Kim, S. (2009). The “instrumentality” heuristic: Why metacognitive difficulty is desirable during goal pursuit. Psychological Science, 20, 127-134. doi:10.1111/j.1467- 
9280.2008.02264.x

Larson, R. \& Wilson, S. (2004). Adolescence across place and time: Globalization and the changing pathways to adulthood. In R. Lerner \& L. Steinberg (Eds.), Handbook of adolescent psychology (pp. 299-330). New York: Wiley.

Lerner, R. M. (1984). On the nature of human plasticity. Cambridge University Press.

Levesque, C., Zuehlke, A. N., Stanek, L. R., \& Ryan, R. M. (2004). Autonomy and competence in German and American university students: A comparative study based on selfdetermination theory. Journal of Educational Psychology, 96, 68-84. doi:10.1037/00220663.96 .1 .68

Little, T. D., Snyder, C. R., \& Wehmeyer, M. (2006). The agentic self: On the nature and origins of personal agency across the lifespan. In D. Mroczek \& T. D. Little (Eds.), Handbook of personality development (pp. 61-80). Mahwah, NJ: LEA.

Mata, R., Josef, A. K., Samanez-Larkin, G. R., \& Hertwig, R. (2011). Age differences in risky choice: A meta-analysis. Annals of the New York Academy of Sciences, 1235, 18-29. doi:10.1111/j.1749-6632.2011.06200.x

Mellers, B.A. (2000). Choice and the relative pleasure of consequences. Psychological Bulletin, 126, 910-924. doi:10.1037/0033-2909.126.6.910

Mustafic, M., \& Freund, A. M. (2012). Multidimensionality in developmental conceptions across adulthood. GeroPsych, 25, 57-72. doi:10.1024/1662-9647/a000055

Napolitano, C. M. (2013). More than just a simple twist of fate: Serendipitous relations in developmental science. Human Development, 56, 291-318. doi:10.1159/000355022

Orehek, E., \& Vazeou-Nieuwenhuis, A. (2013). Sequential and concurrent strategies of multiple goal pursuit. Review of General Psychology, 17, 339-349. doi:10.1037/a0032584 
Overton, W.F. (2010). Life-span development: Concepts and issues. In R.M. Lerner (Ed.), The handbook of life-span development. Vol. 1 (pp. 1-29). Hoboken: Wiley. doi:10.1002/9780470880166.hlsd001001

Peters, E., Hess, T. M., Västfjäll, D., \& Auman, C. (2007). Adult age differences in dual information processes: Implications for the role of affective and deliberative processes in older adults' decision making. Perspectives on Psychological Science, 2, 1-23. doi:10.1111/j.1745-6916.2007.00025.x

Raynor, J. O. (1981). Future orientation and achievement motivation: Toward a theory of personality functioning and change. In G. d'Ydewalle \& W. Lens (Eds.), Cognition in human motivation and learning (pp. 199-231). Leuven, Belgium: Leuven University Press, and Hillsdale, NJ: Erlbaum.

Rolison, J., Hanoch Y., Wood, S., \& Liu, Pi-Ju. (2014). Risk taking differences across the adult lifespan: A question of age and domain. The Journals of Gerontology Series B: Psychological Sciences and Social Sciences, 69, 870-890. doi: doi: 10.1093/geronb/gbt081

Roberts, B.W., Jackson, J.J., Fayard, J.V., Edmonds, G., \& Meints, J. (2009). Conscientiousness. In M.R. Leary \& R.H. Hoyle (Eds.), Handbook of individual differences in social behavior (pp. 369-381). New York: Guilford.

Riediger, M., \& Freund, A. M. (2006). Focusing and restricting: Two aspects of motivational selectivity in adulthood. Psychology and Aging, 21, 173-185. doi:10.1037/08827974.21.1.173

Savage, L. J. (1954). The Foundations of Statistics. New York, Wiley.

Schultheiss, O. C., Jones, N. M., Davis, A. Q., \& Kley, C. (2008). The role of implicit motivation 
in hot and cold goal pursuit: Effects on goal progress, goal rumination, and emotional well-being. Journal of Research in Personality, 42, 971-987.

doi:10.1016/j.jrp.2007.12.009

Schwartz, B. (2004). The paradox of choice. New York: Ecco.

Schwartz, B., Ward, A., Monterosso, J., Lyubomirsky, S., White, K., \& Lehman, D. R. (2002). Maximizing versus satisficing: Happiness is a matter of choice. Journal of Personality and Social Psychology, 83, 1178-1197.

Shah, J. Y., Friedman, R., \& Kruglanski, A. W. (2002). Forgetting all else: On the antecedents and consequences of goal shielding. Journal of Personality and Social Psychology, 83, 1261-1280. doi:10.1037/0022-3514.83.6.1261

Shah, J. Y., \& Kruglanski, A. W. (2008). Structural dynamics: The challenge of change in goal systems. In J. Y. Shah \& W. Gardner (Eds.), Handbook of motivation science (pp. 217229). New York: Guilford Press.

Simon, H. A. (1956). Rational choice and the structure of the environment. Psychological Review, 63, 129-138. doi: $10.1037 / \mathrm{h} 0042769$

Skinner, E. A. (1996). A guide to constructs of control. Journal of Personality and Social Psychology, 71, 549-570. doi:10.1037/0022-3514.71.3.549

Sniehotta, F. F., Schwarzer, R., Scholz, U., \& Schüz, B. (2005). Action planning and coping Planning for long-term lifestyle change: theory and assessment. European Journal of Social Psychology, 35, 565-576. doi:10.1002/ejsp.258

Staudinger, U. M., Marsiske, M., \& Baltes, P. B. (1995). Resilience and reserve capacity in later adulthood: Potentials and limits of development across the life span. In D. Cicchetti \& D. Cohen (Eds.), Developmental psychopathology (Vol. 2, pp. 801-847). New York: Wiley. 
Stadler, G., Oettingen, G., \& Gollwitzer, P. M. (2009). Physical activity in women: Effects of a self-regulation intervention. American Journal of Preventive Medicine, 36, 29-34. doi:10.1016/j.amepre.2008.09.021

Stadler, G., Oettingen, G., \& Gollwitzer, P. M. (2010). Intervention effects of information and self-regulation on eating fruits and vegetables over two years. Health Psychology, 29, 274-283. doi:10.1037/a0018644

Staw, B. M. (1976). Knee-deep in the big muddy: A study of escalating commitment to a chosen course of action. Organizational Behavior and Human Performance, 16, 27-44. doi:10.1016/0030-5073(76)90005-2

Sternberg, R. J., Forsythe, G. B., Hedlund, J., Horvath, J., Snook, S., Williams, W. M., Wagner, R. K., \& Grigorenko, E. L. (2000). Practical intelligence in everyday life. New York: Cambridge University Press

Tomasik, M. J., \& Salmela-Aro, K. (2012). Knowing when to let go at the entrance to university: Beneficial effects of compensatory secondary control after failure. Motivation and Emotion, 36, 170-179. doi:10.1007/s11031-011-9246-5

Tomasik, M. J., \& Silbereisen, R. K. (2012). Social change and adolescent developmental tasks: The case of postcommunist Europe. Child Development Perspectives, 6, 326-334. doi:10.1111/j.1750-8606.2011.00228.x

Vaupel, J. W. (2010). Biodemography of human ageing. Nature, 464, 536-542. doi:10.1038/nature08984

Wagner, R. K., \& Sternberg, R. J. (1985). Practical intelligence in real-world pursuits: The role of tacit knowledge. Journal of Personality and Social Psychology, 49(2), 436. doi: $\underline{10.1037 / 0022-3514.49 .2 .436}$ 
Wiese, B. S., \& Freund, A. M. (2000). The interplay of work and family in young and middle adulthood. In J. Heckhausen (Ed.), Motivational psychology of human development: Developing motivation and motivating development (pp. 233-250). Amsterdam, Netherlands: Elsevier.

Winkielman, P., Schwarz, N., Fazendeiro, T., \& Reber, R. (2003). The hedonic marking of processing fluency: Implications for evaluative judgment. In J. Musch \& K.C. Klauer (Eds.), The Psychology of Evaluation: Affective Processes in Cognition and Emotion. (pp. 189-217). Mahwah, NJ: Erlbaum.

Wrosch, C., \& Freund, A. M. (2001). Self-regulation of normative and non-normative developmental challenges. Human Development, 44, 264-283. doi:10.1159/000057066

Wrosch, C., Bauer, I., \& Scheier, M. F. (2005). Regret and quality of life across the adult life span: the influence of disengagement and available future goals. Psychology and Aging, 20, 657-670. doi:10.1037/0882-7974.20.4.657 


\section{Endnotes}

${ }^{1}$ Throughout this article, we use costs and benefits (common to the economics literature) interchangeably with losses and gains (common to the life-span developmental psychological literature), respectively.

${ }^{2}$ For researchers, more nuanced calculations of complexity value are possible. For example, for goals where a particular resource is highly instrumental for goal achievement (e.g., time for the photographer), one may disaggregate this global formula and assign a higher "weight" for that resource and comparatively lower weights for other resources. These weights can change, and are therefore dynamic across the goal pursuit. In addition, the point-in-time or cumulative influence of combinations of resources (e.g., time and motivation) on complexity value may be additive, multiplicative, or some other combination. For the purposes of this narrative, we present only the simplest, global formula for complexity value. 


\section{Figure Captions}

Figure 1. A prototypical example of changes in complexity value when using a redundant backup plan.

Figure 2. A prototypical example of changes in complexity value when using a contingent backup plan. 


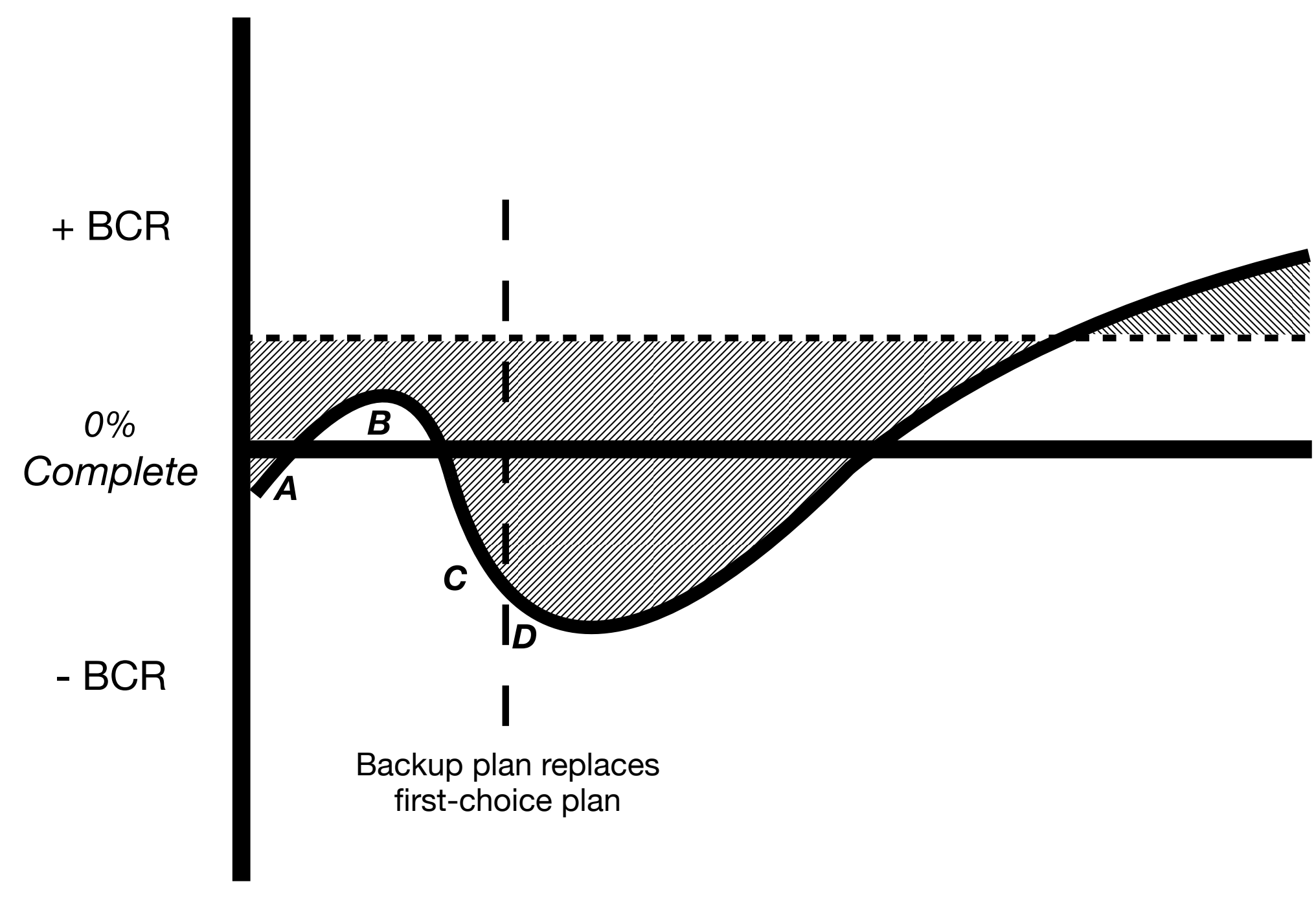

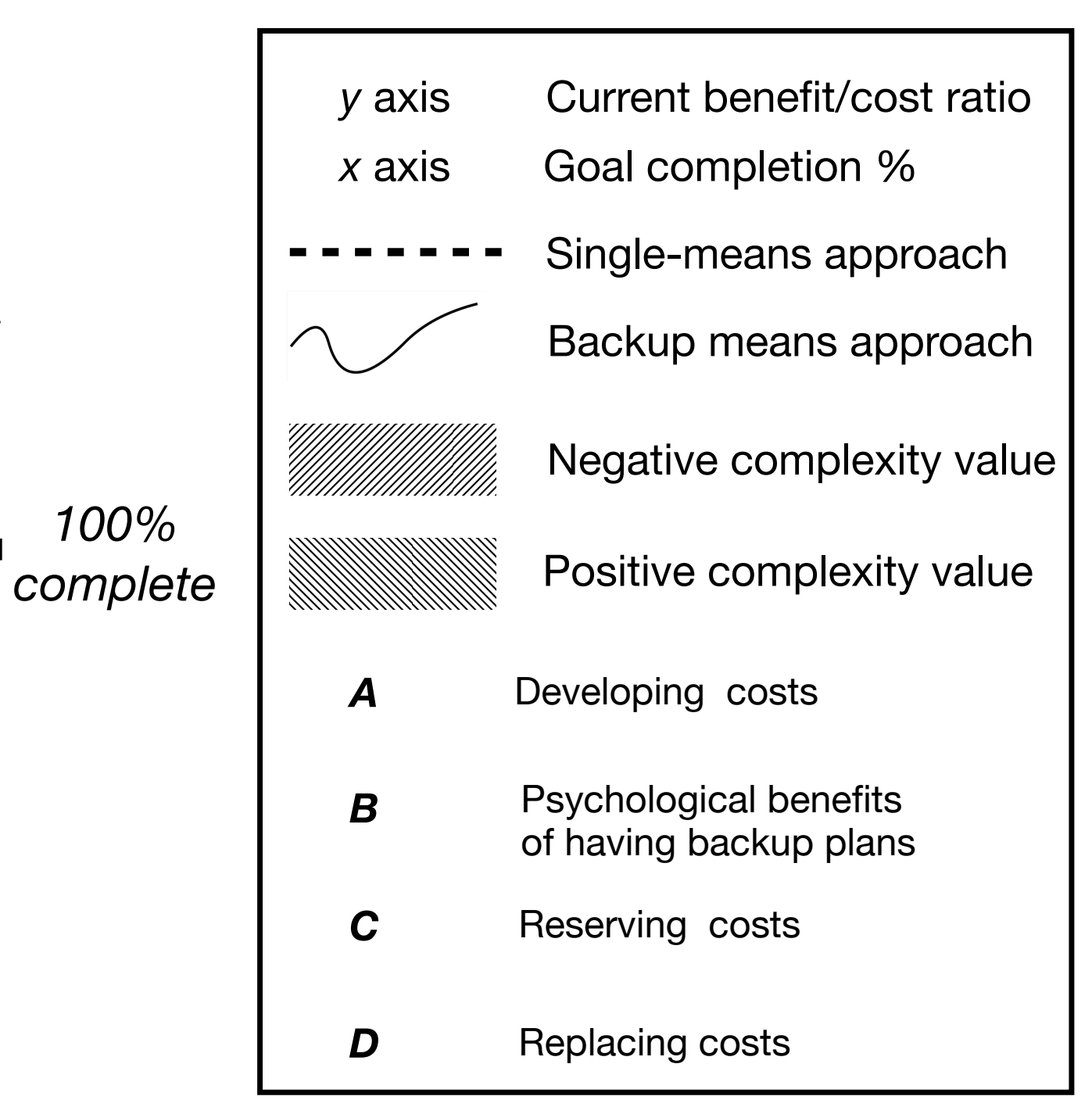




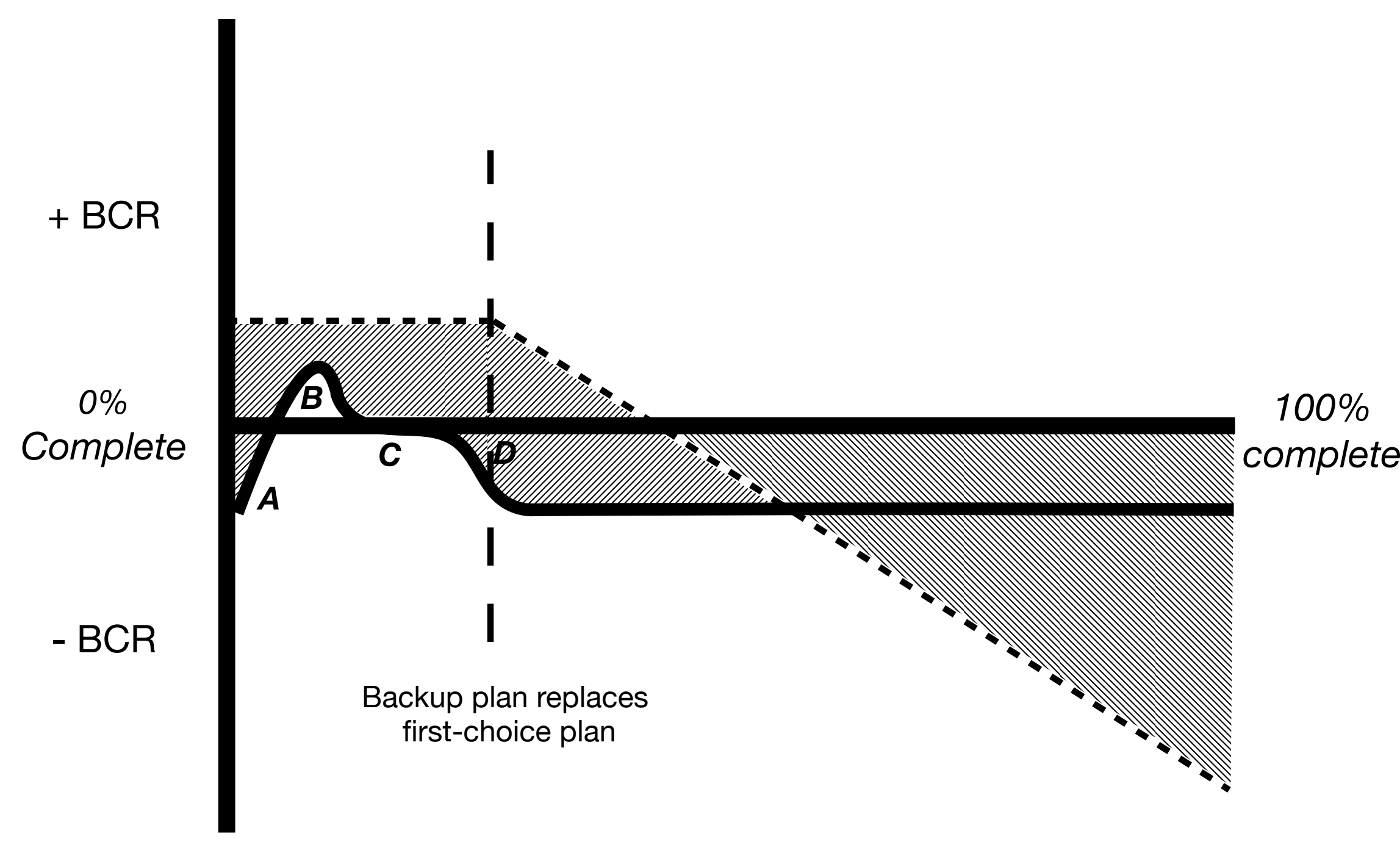

\begin{tabular}{|c|c|}
\hline$y$ axis & Current benefit/cost ratio \\
\hline \multirow{5}{*}{$x$ axis } & Goal completion \% \\
\hline & Single-means approach \\
\hline & Backup means approach \\
\hline & Negative complexity value \\
\hline & Positive complexity value \\
\hline $\boldsymbol{A}$ & Developing costs \\
\hline B & $\begin{array}{l}\text { Psychological benefits } \\
\text { of having backup plans }\end{array}$ \\
\hline C & Reserving costs \\
\hline$D$ & Replacing costs \\
\hline
\end{tabular}

